\title{
Carcinoide neuroendócrino hepático em uma vaca
}

Adony Q Andrade Neto", Jose Augusto B Afonso, Rodolfo JC Souto, Carla L Mendonça, José Claudio A Souza

Programas de Pós-Graduação em Ciência Veterinária, Universidade Federal Rural de Pernambuco (UFRPE), Guarunhos, PE, Brasil

*Autor correspondente

e-mail: adony_neto@hotmail.com

\section{Resumo}

O sistema de células neuroendócrinas é composto pelos tipos celulares que formam as glândulas endócrinas e aquelas difusamente distribuídas por todo o corpo, incluindo a pele, pulmões, trato gastrointestinal e trato hepatobiliar. Estas são chamadas de células APUD, células da descarboxilação celular, precursoras de amina ou células enterocromafínicas. As neoplasias carcinoides originam-se a partir da crista neural, migrando para fora da camada ectodérmica, ou a partir da camada endodérmica ou de precursores amino capturados da descarboxilação (APUD) celular. 0 presente estudo tem por objetivo relatar a ocorrência de um tumor carcinoide neuroendócrino hepático em uma vaca, enfocando os aspectos clínicos, anatopatológicos e histológicos desta neoplasia de ocorrência pouco frequente em bovinos. Uma vaca mestiça de Pardo Suíça, aproximadamente 6 anos de idade, foi atendida na Clínica de Bovinos-UFRPE, apresentando anorexia e distúrbios no comportamento e na postura. No exame físico foi constatado alterações nervosas, digestivas e comportamentais. 0 curso clínico durou sete dias ,e em decorrência da evolução clínica desfavorável , o animal foi sacrificado e necropsiado. Os principais achados laboratoriais evidenciaram na hematologia policitemia absoluta, hemoglobina elevada, com volume corpuscular médio normocítico e concentração de hemoglobina corpuscular média normocromica e proteína plasmática normal, neutrofilia com desvio a esquerda regenerativo e hiperfibrinogenemia. A bioquímica clínica revelou níveis elevados de gamaglutamiltrasferase (GGT), baixos de albumina e elevados de globulina. 0 principal achado anatomopatológico foi o fígado que se encontrava aumentado e com uma massa tumoral de aproximadamente 20x15x15 cm aderido ao órgão, em formato ovoide, com cápsula amarelada, consistência firme e localizado adjacente a veia porta. Na histologia foi compatível com neoplasia do tipo carcinoide neuroendócrino hepático primário. Conclui-se que casos de tumores hepáticos do tipo carcinoide neuroendócrino tratam-se de uma enfermidade que impõe uma condição clínica grave, intratável, e com desfecho desfavorável. 